\title{
Marked Differences in Light-Switch Behavior of Ru(II) Complexes Possessing a Tridentate DNA Intercalating Ligand
}

\author{
Yao Liu,${ }^{\S}$ Richard Hammitt, ${ }^{\dagger}$ Daniel A. Lutterman, ${ }^{\S}$ Randolph P. Thummel, ${ }^{\dagger}, *$ \\ and Claudia Turro $\$$,*
}

\section{Supporting Information}

Figure $\mathrm{S} 1$ shows the changes to the absorption spectrum of $12.5 \mu \mathrm{M}[\mathrm{Ru}(\mathrm{tpy})(\mathrm{pydppz})]^{2+}$ upon addition of increasing DNA concentrations $(0-74 \mu \mathrm{M})$ in $5 \mathrm{mM}$ Tris $50 \mathrm{mM} \mathrm{NaCl}$ buffer $(\mathrm{pH}=7.4)$. The fit to the changes in the absorption used to calculate the DNA binding constant of the complex monitored at $475 \mathrm{~nm}$ are shown in Figure S2 (see text).

Figure S3 shows the changes in absorption in the bleaching region at $480 \mathrm{~nm}$ as a function of time following the excitation pulse. The 2-D ${ }^{1} \mathrm{H}$ NMR spectra of the ligand pydppz and the homoleptic complex, $\left[\mathrm{Ru}(\mathrm{pydppz})_{2}\right]^{2+}$ are shown in Figures S4 and S5, respectively.

The energy values obtained from the calculations are listed in Tables S1 and S2, and selected low-lying unoccupied molecular orbitals of the complexes shown in Figure S6. 

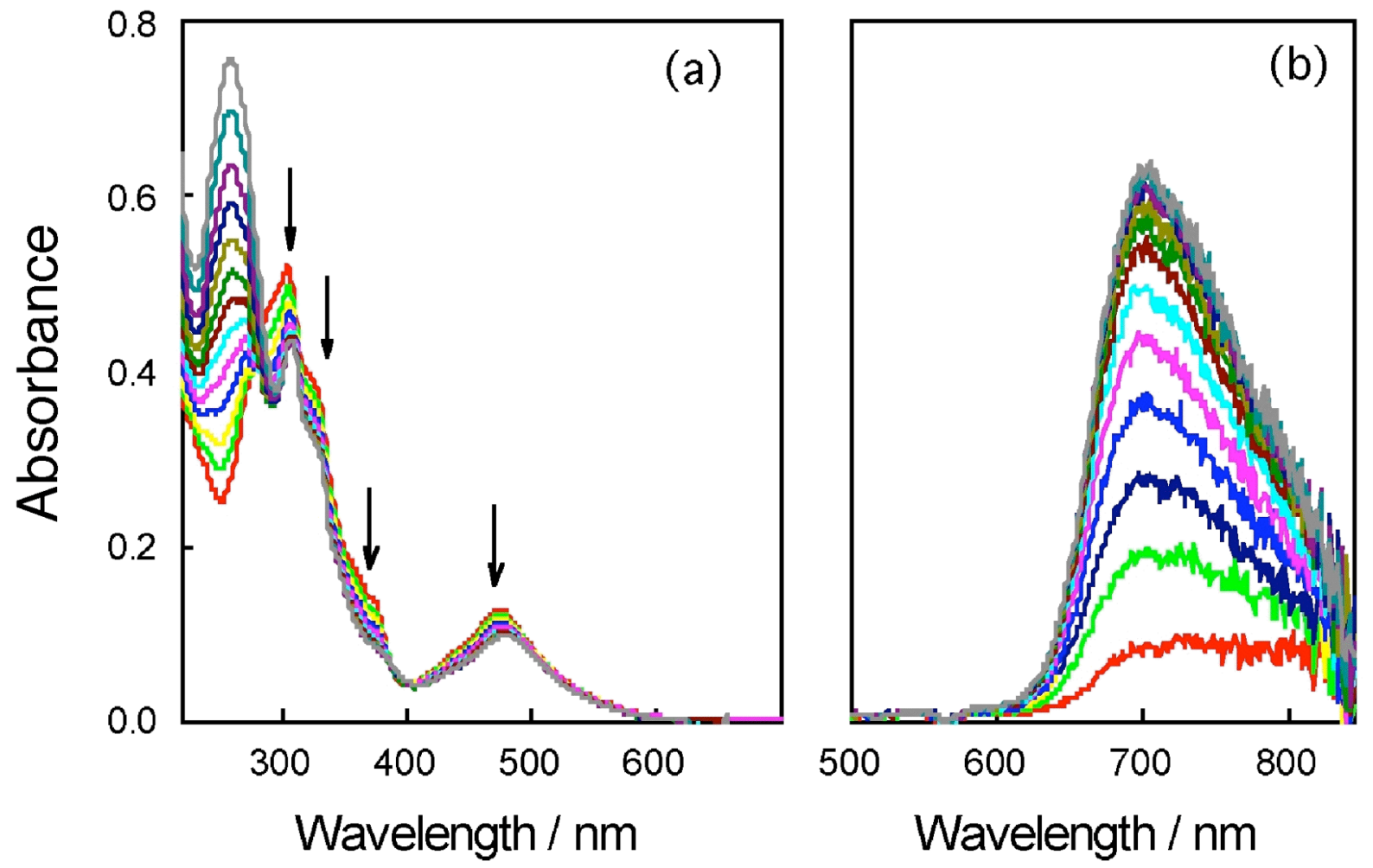

Figure S1. (a) Changes to the absorption spectrum and (b) increase emission intensity of 12.5 $\mu \mathrm{M}[\mathrm{Ru}(\mathrm{tpy})(\mathrm{pydppz})]^{2+}$ upon the addition of up to $74 \mu \mathrm{M} \mathrm{DNA}(5 \mathrm{mM}$ Tris, $50 \mathrm{mM} \mathrm{NaCl}$, $\mathrm{pH}=7.4)$. 


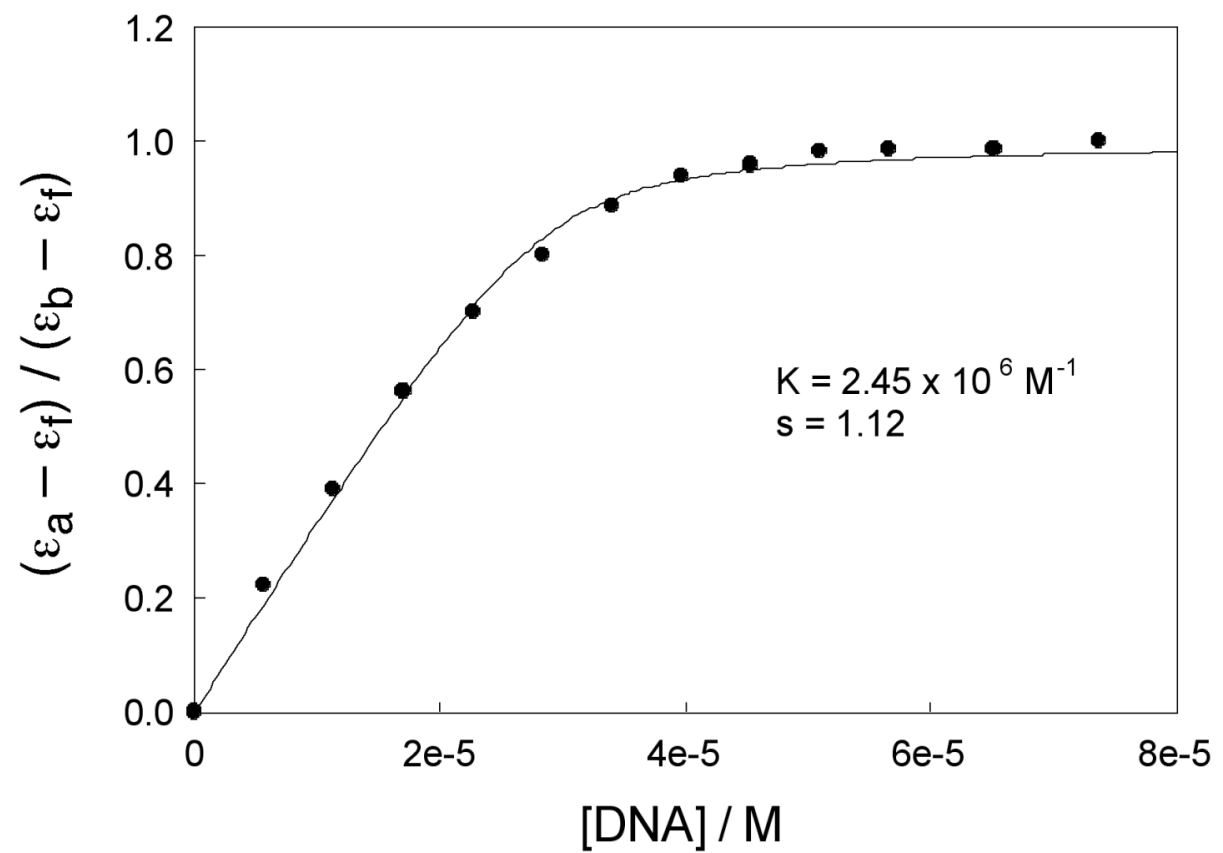

Figure S2. Fit to eq 1 (see text) of the changes in absorption of $12.5 \mu \mathrm{M}$ $\left[\mathrm{Ru}(\text { tpy)(pydppz) }]^{2+}\right.$ monitored at _ $\mathrm{nm}$ upon addition of DNA $(5 \mathrm{mM}$ Tris, $\mathrm{pH}$ $=7.4,50 \mathrm{mM} \mathrm{NaCl})$.

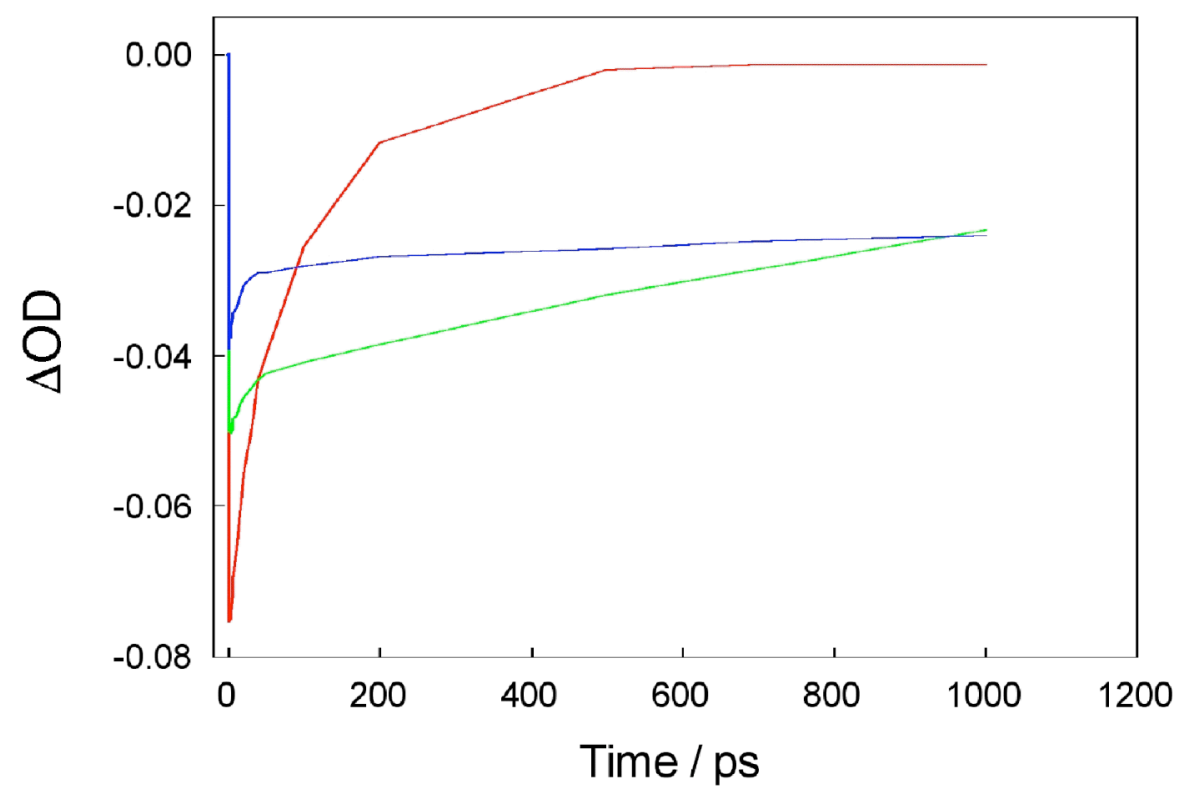

Figure S3. Decay of the time resolved signal measured at $480 \mathrm{~nm}$ for $\left[\mathrm{Ru}(\text { tpy })_{2}\right]^{2+}$ (red), $[\mathrm{Ru}(\mathrm{tpy})(\mathrm{pydppz})]^{2+}$ (green), and $\left[\mathrm{Ru}(\mathrm{pydppz})_{2}\right]^{2+}$ (blue) following the excitation pulse $(310 \mathrm{~nm}, 300 \mathrm{fs})$. 


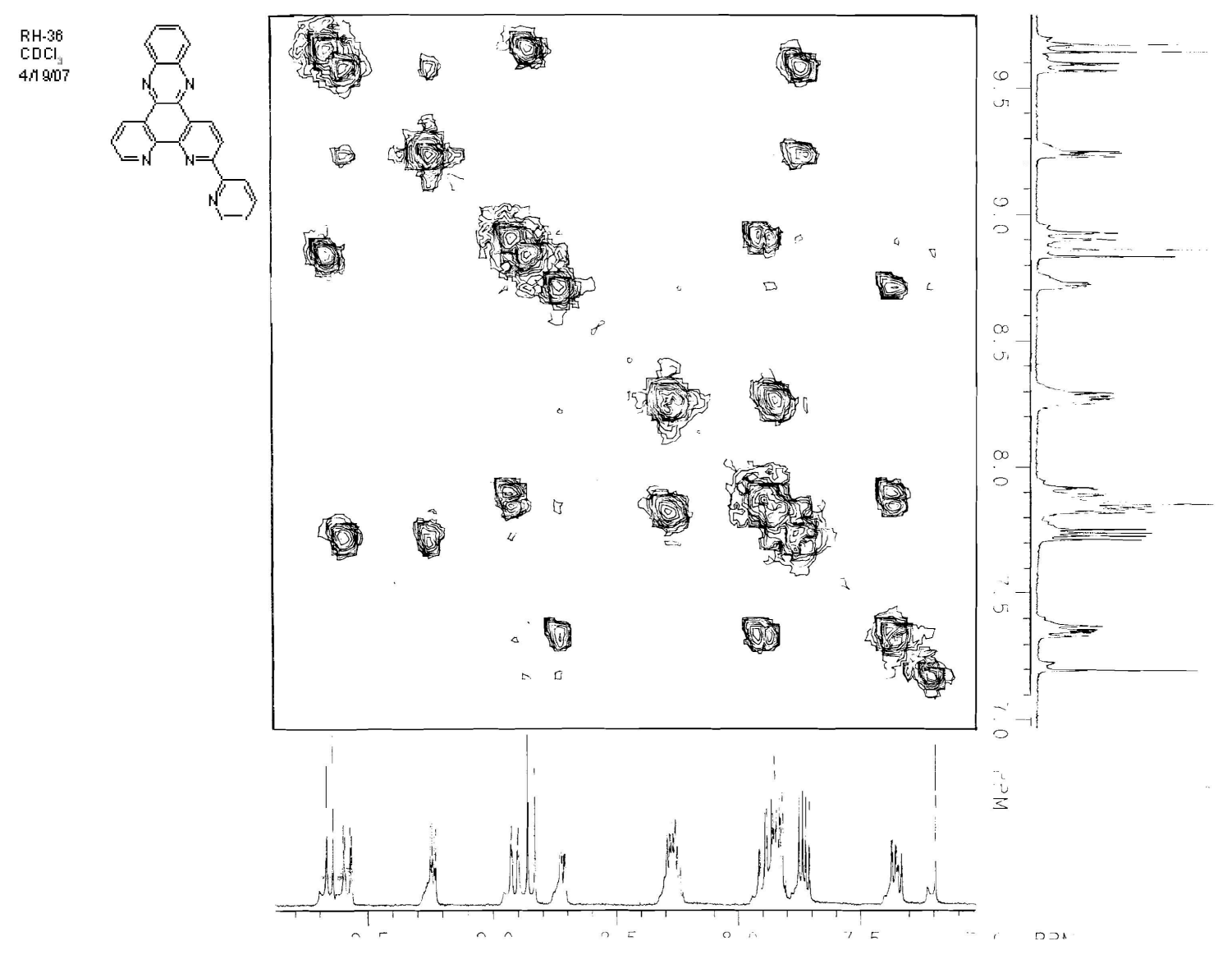

Figure S4. 2D-COSY ${ }^{1} \mathrm{H}$ NMR spectrum of pydppz (3) in $\mathrm{CDCl}_{3}$ at $25{ }^{\circ} \mathrm{C}$. 


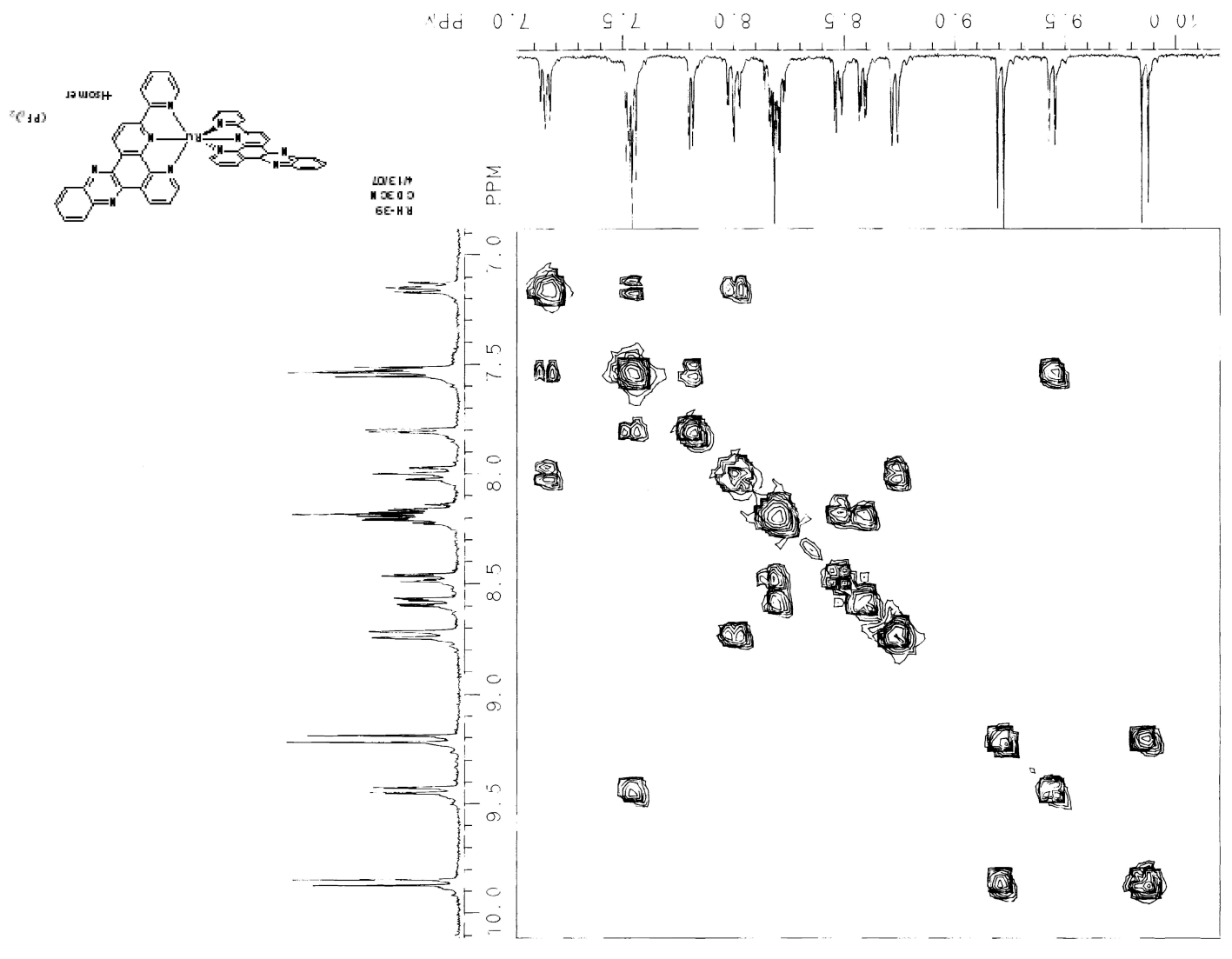

Figure S5. 2D-COSY ${ }^{1} \mathrm{H}$ NMR spectrum of $\left[\mathrm{Ru}(\mathrm{pydppz})_{2}\right]\left(\mathrm{PF}_{6}\right)_{2}$ in $\mathrm{CD}_{3} \mathrm{CN}$ at $25{ }^{\circ} \mathrm{C}$. 
Table S1. TDDFT vertical singlet transitions calculated for $\left[\operatorname{Ru}(\text { tpy })_{2}\right]^{2+},[\operatorname{Ru}(\mathrm{tpy})(\mathrm{pydppz})]^{2+}$, and $\left[\mathrm{Ru}(\mathrm{pydppz})_{2}\right]^{2+}$ in $\mathrm{CH}_{3} \mathrm{CN}$, with transition assignments for $[\mathrm{Ru}(\mathrm{tpy})(\mathrm{pydppz})]^{2+} \cdot{ }^{a}$

\begin{tabular}{|c|c|c|c|}
\hline \multicolumn{3}{|c|}{$\lambda_{\mathrm{abs}} / \mathrm{nm}(f)$} & \multirow{2}{*}{$\begin{array}{c}\text { Assignments for } \\
{[\operatorname{Ru}(\text { tpy })(\text { pydppz })]^{2+b}}\end{array}$} \\
\hline$\left[\mathrm{Ru}(\mathrm{tpy})_{2}\right]^{2+}$ & {$[\mathrm{Ru}(\mathrm{tpy})(\mathrm{pydppz})]^{2+}$} & {$\left[\mathrm{Ru}(\mathrm{pydppz})_{2}\right]^{2+}$} & \\
\hline & & $419(0.0017)$ & \\
\hline $411(0.0194)$ & $407(0.0396)$ & $440(0.2715)$ & $\operatorname{Ru}\left(\mathrm{d}_{\pi}\right) \rightarrow \operatorname{tpy} / \operatorname{pydppz}\left(\pi^{*}\right)$ \\
\hline $411(0.0197)$ & $407(0.0016)$ & $443(0.0004)$ & $\operatorname{Ru}\left(\mathrm{d}_{\pi}\right) \rightarrow \operatorname{tpy} / \operatorname{pydppz}\left(\pi^{*}\right)$ \\
\hline $413(0.0235)$ & $427(0.0030)$ & $446(0.0017)$ & $\operatorname{Ru}\left(\mathrm{d}_{\pi}\right) \rightarrow \operatorname{tpy} / \operatorname{pydppz}\left(\pi^{*}\right)$ \\
\hline $413(0.0228)$ & $441(0.2032)$ & $450(0.0033)$ & $\operatorname{Ru}\left(\mathrm{d}_{\pi}\right) \rightarrow \operatorname{pydppz}\left(\pi^{*}\right)$ \\
\hline $414(0.1368)$ & $451(0.0000)$ & $455(0.1172)$ & $\operatorname{Ru}\left(\mathrm{d}_{\pi}\right) \rightarrow \operatorname{pydppz}\left(\pi^{*}\right)$ \\
\hline $432(0.0000)$ & $460(0.0241)$ & $464(0.0514)$ & $\operatorname{Ru}\left(\mathrm{d}_{\pi}\right) \rightarrow \operatorname{pydppz}\left(\pi^{*}\right)$ \\
\hline $441(0.0693)$ & $463(0.0006)$ & $466(0.0369)$ & $\operatorname{Ru}\left(\mathrm{d}_{\pi}\right) \rightarrow \operatorname{tpy}\left(\pi^{*}\right)$ \\
\hline $464(0.0000)$ & $472(0.0450)$ & $480(0.0001)$ & $\operatorname{Ru}\left(\mathrm{d}_{\pi}\right) \rightarrow \operatorname{pydppz}\left(\pi^{*}\right)$ \\
\hline $476(0.0000)$ & $474(0.0120)$ & $490(0.0006)$ & $\operatorname{Ru}\left(\mathrm{d}_{\pi}\right) \rightarrow \operatorname{tpy}\left(\pi^{*}\right)$ \\
\hline $481(0.0128)$ & $494(0.0000)$ & $500(0.0012)$ & $\operatorname{Ru}\left(\mathrm{d}_{\pi}\right) \rightarrow \operatorname{pydppz}\left(\pi^{*}\right)$ \\
\hline $481(0.0128)$ & $507(0.0038)$ & $500(0.0063)$ & $\operatorname{Ru}\left(\mathrm{d}_{\pi}\right) \rightarrow \operatorname{pydppz}\left(\pi^{*}\right)$ \\
\hline
\end{tabular}

${ }^{a}$ All calculated transitions at $\lambda \geq 400 \mathrm{~nm}$ are ${ }^{1}$ MLCT in character. ${ }^{b}$ All of the ${ }^{1}$ MLCT transitions listed for $\left[\mathrm{Ru}(\mathrm{tpy})_{2}\right]^{2+}$ and $\left[\mathrm{Ru}(\mathrm{pydppz})_{2}\right]^{2+}$ are $\operatorname{Ru}(\mathrm{d} \pi) \rightarrow \operatorname{tpy}\left(\pi^{*}\right)$ and $\operatorname{Ru}(\mathrm{d} \pi) \rightarrow \operatorname{pydppz}\left(\pi^{*}\right)$, respectively. The transition assignments for $[\mathrm{Ru}(\mathrm{tpy})(\mathrm{pydppz})]^{2+}$ are based on the character of the orbitals with most weight. 
Table S2. Energies of the Five Lowest Vertical Triplet Electronic Transitions, $\mathrm{E}_{\mathrm{T}}$, of the Complexes Calculated Using TDDFT in $\mathrm{CH}_{3} \mathrm{CN}$.

\begin{tabular}{ccc}
\hline \multicolumn{3}{c}{$\mathrm{E}_{\mathrm{T}} / \mathrm{eV}(\lambda / \mathrm{nm})$} \\
\hline$\left[\mathrm{Ru}(\mathrm{tpy})_{2}\right]^{2+}$ & {$[\mathrm{Ru}(\mathrm{tpy})(\mathrm{pydppz})]^{2+}$} & {$\left[\mathrm{Ru}(\mathrm{pydppz})_{2}\right]^{2+}$} \\
\hline $2.229(556)$ & $2.155(575)$ & $2.163(573)$ \\
$2.290(541)$ & $2.337(531)$ & $2.186(567)$ \\
$2.386(520)$ & $2.409(515)$ & $2.315(536)$ \\
$2.386(520)$ & $2.482(500)$ & $2.360(525)$ \\
$2.505(495)$ & $2.511(494)$ & $2.377(522)$ \\
\hline
\end{tabular}




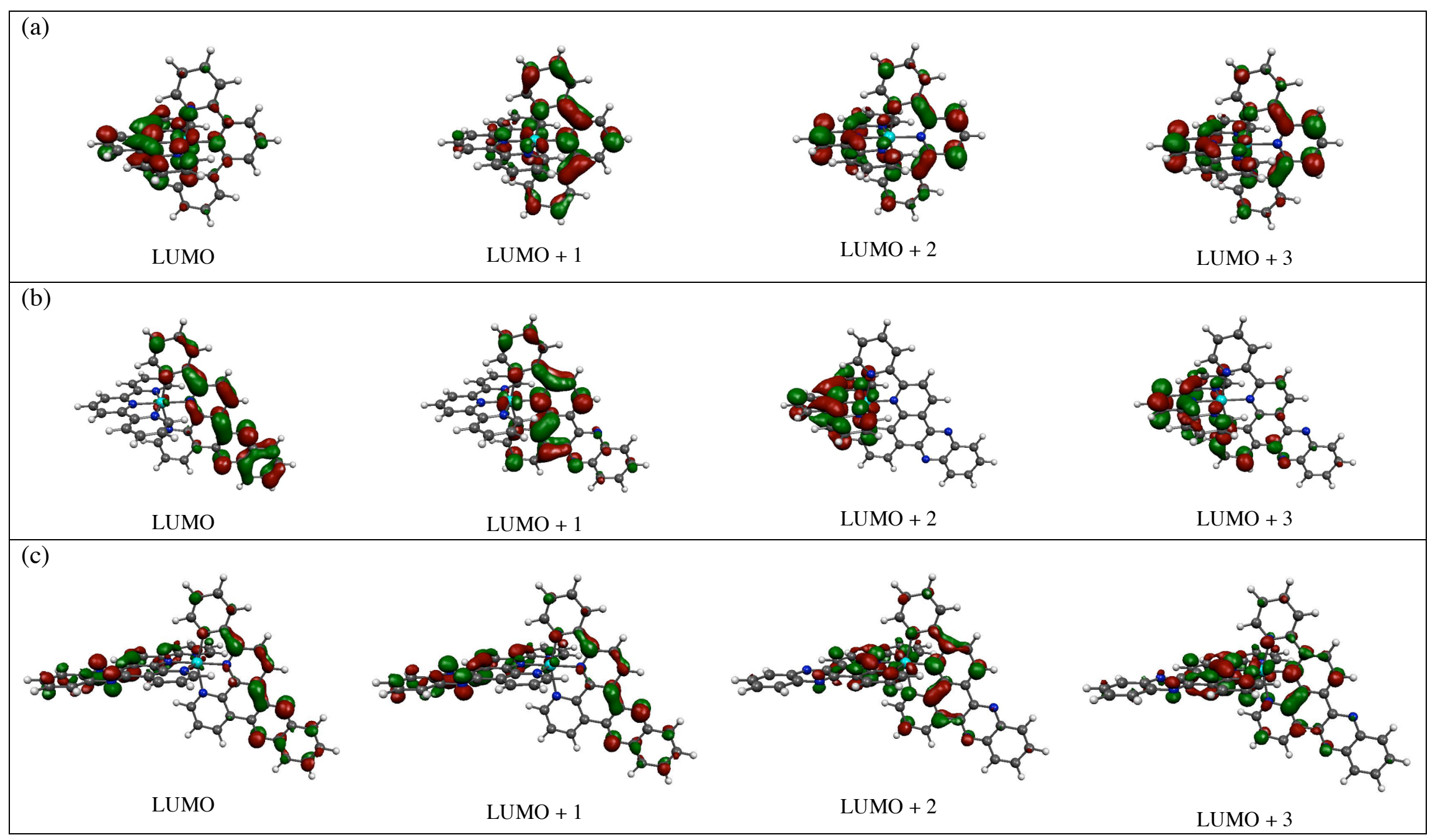

Figure S6. Unoccupied MOs of (a) $\left[\mathrm{Ru}(\mathrm{tpy})_{2}\right]^{2+}$, (b) $[\mathrm{Ru}(\mathrm{tpy})(\mathrm{pydppz})]^{2+}$, and (c) $\left[\mathrm{Ru}(\mathrm{pydppz})_{2}\right]^{2+}$ in $\mathrm{CH}_{3} \mathrm{CN}$ (isovalue $=0.035$ ). 